\title{
PHYLOGENETIC AND HISTOPATHOLOGICAL CHARACTERIZATION OF NEWCASTLE DISEASE VIRUSES REVEALS HIGH PREVALENCE OF VERY VIRULENT STRAINS OF GENOTYPE VIID IN EGYPT
}

\author{
NAGLAA M. HAGAG; ALY M. ZANATY; MOHAMED A. SOLIMAN; MAHMOUD SAIED; \\ A. ARAFA and M.K. HASSAN \\ National Laboratory for Veterinary Quality Control on Poultry Production, P.O. Box 264, Dokki, Giza.
}

Received: 21 July 2016; Accepted: 31 July 2016

\begin{abstract}
Newcastle disease virus (NDV) is a highly contagious disease in poultry, also considered as a major challenge for the commercial and traditional poultry industry in Egypt. In this study clinicopathological and immunohistochemistry examination of fourteen flocks from different provinces in Egypt during 2013 and 2014 revealed velogenic ND features and positive staining for ND virus (NDV) antigen in pantropic organs of all strains which also revealed positive NDV by RRT-PCR, as it is alreadyconvinced that the fusion protein cleavage site has been deemed as responsible for the pathogenicity of NDV and selected as a target to identify and type lentogenic and velogenic strains, viral Genomic RNAs were extracted from representing swabs and organs of examined flocks, and partially amplifiedfor fusion gene of NDV using RT-PCR, then forwarded to gene sequencing. Four chosen samples amplified for full fusion gene sequence using specific sets of newly designed primers from the available sequence data of NDV strains in Gen Bank, The resulted sequence showed motif ${ }^{112} \mathrm{RRQKRF}^{117}$ which is indicative of velogenic character NDV strains, and indicate presence of 2 mutations E74D and D170N in two strains. Phylogenetic analysis revealed that Egyptian strains are closely related to NDV genotype VIId strains of south East Asian countries based on the high nucleotide and amino acid similarity.
\end{abstract}

Key words: NDV, RRT-PCR, RT-PCR, Full Fusion gene (F gene), Immunohistopathology, and Molecular evolution.

\section{INTRODUCTION}

Newcastle disease (ND) is one of the major concerns of poultry industry in the world. It is caused by Newcastle disease virus (NDV), a member of avian paramyxovirus (APMV), which belongs to the genus Avulavirus, sub-family Paramyxovirinae, family Paramyxoviridae, and order Mononegavirales (Mayo,2002). Its single-stranded RNA genome is composed of 6 genes, -NP-P-M-F-HN-L, encoding 6 major proteins nucleoprotein (NP), phosphoprotein (P), matrix protein (M), fusion protein (F), hemagglutinin-neuraminidase $(\mathrm{HN})$, and large protein (L), respectively. The hemagglutinin-neuraminidase (HN) and the fusion (F) proteins are both glycoproteins expressed at the surface of the enveloped virus. They mediate attachment of the viral particle to

Corresponding author: Dr. NAGLAA M. HAGAG

E-mail address: naglaavetrose@yahoo.com

Present address: National Laboratory for Veterinary Quality

Control on Poultry Production, P.O. Box 264, Dokki, Giza. sialic acid-containing cell receptors, its fusion with the plasma cell membrane, and the release of progeny virions from the surface of infected cells (Lamb and Parks, 2007). Both proteins also induce virusneutralizing antibody responses; $\mathrm{F}$ protein is regarded as an important pathogenic marker of NDV (Rott et al., 1988). This important pathogen remains havoc for the poultry industry and causes a severe economic impact in terms of heavy production losses and high mortality. Newcastle disease virus (NDV) has a wide host range, including approximately 241 species of 27 orders, out of known 50 orders of birds (Madadger et al., 2013). The most susceptible avian species to this disease are chickens (Rezaeianzadeh et al., 2011). Depending upon the pathotype and susceptibility the mortality varies from zero to $100 \%$ (Nanthakumar et al., 2000).

Several pathotypes (asymptomatic enteric, lentogenic, mesogenic, viscerotropic velogenic, or neurotropic velogenic) of NDV are recognized depending on the clinical symptoms observed in chickens (OIE. 2012). 
A virulent and virulent strainmay also be distinguished on the basis of the cleavage site sequence of their $F$ protein. During replication, the fusion gene is translated into a precursor protein, F0, which must be cleaved by host cell proteases into F1 and F2 subunits for viral particles to become infectious (Morrison et al., 1993). Most virulent strains exhibit the consensus sequence ${ }^{112}(\mathrm{R} / \mathrm{K}) \mathrm{RQ}(\mathrm{R} / \mathrm{K}) \mathrm{R}^{*} \mathrm{~F}^{117}$ at the cleavage site of the F0 precursor, in contrast to ${ }^{112}(\mathrm{G} / \mathrm{E})(\mathrm{K} / \mathrm{R}) \mathrm{Q}$ (G/E) $\mathrm{R}^{*} \mathrm{~L}^{117}$ in a virulent viruses (Collins et al., 1993; OIE. 2012). The genomic diversity of NDV increases the possibility of diagnostic failures, resulting in unidentified infections (Miller et al., 2010).

In Egypt, velogenic strains of NDV were isolated and clustered as class II genotype VII sub-genotype d and closely related to Middle East isolates (Radwan et al., 2013). The predominant NDV isolates circulating among chickens are virulent and associated with outbreaks in commercial poultry farms and backyard reared chickens in Egypt (Osman et al., 2014). Phylogenetic analysis of some strains isolated from Egypt was closely related to the NDV strains isolated previously in China. Determination of complete genome sequences of additional NDV strains from Africa is necessary to understand the epidemiology of currently circulating viruses in Africa (Mohamed et al., 2009).

Herein, detection and characterization of Newcastle disease virus (NDV) from recent outbreaks affecting poultry farms in Egypt between 2011 and 2014 were conducted. Partial amplification and sequence of the F gene covering the cleavage site for 14 isolate were done, also full fusion sequence for 4 selected isolates were also done. In the current work we aimed to(a)Determine the circulating NDV genotype and causing the severe outbreaks in poultry farms. (b)Phylogeny of Egyptian strains and determine the potential source of these strains. (c) Determine the genetic relation between different NDV vaccinal strains and the current circulating strains.

\section{MATERIALS AND METHODS}

\section{Sample collection:}

The samples; organs (Brain, trachea, lungs, proventriculus, small intestine and pancreas) and swabs (cloacal and tracheal) from fourteen chicken broiler farms including different Egyptian governorates showed respiratory, nervous signs and diarrhea, sudden onset high mortality. These samples were labeled and transported immediately on ice to the reference laboratory for quality control on poultry production (RLQP) to be processed immediately for RRT-PCR.

\section{Detection of NDV by RRT-PCR}

The viral genomic RNAs of 14 sample were extracted from the infective coloacal and tracheal swabs and also from organs using QiAmp Viral RNA Mini kit (Qiagen GmbH, Hilden, Germany) according to the manufacturer's instructions, RRT-PCR was carried out using a commercial kit Quantitect probe RT-PCR kit (Qiagen, Inc. Valencia CA).Primers usedNDV-F (F+4829) 5'-GGT GAG TCT ATC CGG ARG ATA CAA G-3', NDV-R (F-4939) 5'-TCA TTG GTT GCR GCA ATG CTC T-3' and probe- (F+4894) 5'-FAMAAG CGT TTC TGT CTC CTT CCT CCA-BHQ3'(Creelan et al., 2002 and Ausvetplan, 2006). RRTPCR was conducted in the Stratagene 3005P MXpro Real-Time PCR System (Stratagene, USA) according to manufacture instructions.

\section{Histopathology and immunohistochemistry (IHC)}

Brain, trachea, lungs, proventriculus, small intestine and pancreas were collected tissues were fixed by submersion in $10 \%$ neutral buffered formalin and embedded in paraffin. Sections were made at $5 \mu \mathrm{m}$ and were stained with hematoxylin and eosin (HE). For immunohistochemistry a $4 \mu \mathrm{m}$ section was antigen retrieved by first microwaving the sections in Antigen Retrieval Citra Solution (Biogenex) for antigen exposure.Nonspecific protein and endogenous peroxidase were blocked by incubation for 5 minutes with blocking reagents from the polymer kit. A 1:500 dilution of a mouse-derived monoclonal antibody (Novus Bio) specific for NDV nucleoprotein was applied and allowed to incubate for $30 \mathrm{~min}$. at $37{ }^{\circ} \mathrm{C}$. The primary antibody was then detected by the application of peroxidase rabbit anti-mouse IgG secondary antibody using Mouse and Rabbit Specific HRP/3, 3' Diaminobenzidine DAB Detection IHC (Abcam) and hematoxylin was used as a counterstain then mounted by depex (Susta et al., 2011).

\section{Primer design for RT-PCR and sequence of fusion gene}

PCR amplification was performed by using Qiagen One Step Enzyme Mix according to the manufacturer's instructions, using primer sets designed from the available sequences of NDV strains from Gen Bank (Table 1). Gel containing DNA band of the expected size (766 bP for partially sequenced samples and $1700 \mathrm{bp}$ for full fusion sequence) was excised and purified with the QIAquick Gel Extraction Kit (Qiagen) according to the manufacturer instruction. 
Table 1: Primers used for sequence of partial and complete fusion gene

\begin{tabular}{lcrcc}
\hline Primer name & Direction & Primers & Location & Reference \\
\hline NDV-F330 & Forward & AGG AAG GAG ACA AAA ACG TTT TAT AGG & $\mathbf{3 3 0 - 3 5 7}$ & This study \\
\hline NDV-R700 & Reverse & TCA GCT GAG TTA ATG CAG GGG AGG & $\mathbf{7 0 0 - 6 7 6}$ & This study \\
\hline NDV-F640 & Forward & CTA ACT GAA TTA ACT ACA GTA TTC GGG & $\mathbf{6 4 0 - 6 6 7}$ & This study \\
\hline NDV-R1290 & Reverse & GTC TAA TGA TAA GAC ATT GCA CGA ATG & $\mathbf{1 2 7 9 - 1 2 9 0}$ & This study \\
\hline NDV-F1200 & Forward & ATG TAC AGA CCC TCC TGG TAT CAT ATC & $\mathbf{1 2 0 0 - 1 2 2 7}$ & This study \\
\hline NDV-R1740 & Reverse & CTT AAG TCT TAT ACT TGA CAG GTT ATC & $\mathbf{1 7 1 3 - 1 7 4 0}$ & This study \\
\hline NDV-M2 & Forward & TGG AGC CAA ACC CGC ACC TGCGG & Mase et al., \\
& & & $\mathbf{2 0 0 2 .}$ \\
\hline NDV-F2 & Reverse & GGA GGA TGT TGG CAG CATT & Mase et al., \\
& & & $\mathbf{2 0 0 2 .}$ \\
\hline
\end{tabular}

Sequence and phylogenetic analysis

Purified RT-PCR products were sequenced using Bigdye Terminator V3.1 cycle sequencing kit (Perkin-Elmer, Foster city, CA) and Applied Biosystems 3130 genetic analyzer (ABI, USA). Sequences similarities and relationships of the partial (14 samples) and full fusion gene (4 samples) obtained in this study were compared with previously published NDV vaccine and references strains available in the public database (BLAST, NCBI, USA). Amino acid phylogenetic relationship was constructed for the sequenced samples and other vaccine, reference and Egyptian strains previously published and available on the Gen Bank database using MEGA version 6 (Tamura et al., 2013). A comparative analysis of deduced amino acids and nucleotides sequences of the sequenced fusion gene were created using the CLUSTAL W Multiple Sequence Alignment Program, version 1.83 of Meg Align module of Lasergene DNA Star software. Sequences generated in the frame of this study were submitted to the Gen Bank database with accession numbers as showed in table (2).

Table 2: Epidemiological and genetic data of the sequenced strains in the current study

\begin{tabular}{clcccc}
\hline & Sample code & Governorates & production & $\begin{array}{c}\text { Collection } \\
\text { date }\end{array}$ & $\begin{array}{c}\text { Accession } \\
\text { number }\end{array}$ \\
\hline $\mathbf{1}$ & NDV-FU4-EGYPT-NLQP-2013 & Al-Gharbia & Backyard & $4-2013$ & KU365650 \\
\hline $\mathbf{2}$ & NDV-FU5-EGYPT-NLQP-2014 & Behera & Backyard & $8-2014$ & KU365653 \\
\hline $\mathbf{3}$ & NDV-FU8-EGYPT-NLQP-2014 & Monofia & Farm & $9-2014$ & KU365651 \\
\hline $\mathbf{4}$ & NDV-FU13-EGYPT-NLQP- & Al-Gharbia & Farm & $4-2014$ & KU365652 \\
\hline $\mathbf{5}$ & NDV-1-EGYPT-NLQP-2014 & Al-Gharbia & Farm & $6-2014$ & KU365654 \\
\hline $\mathbf{6}$ & NDV-2-EGYPT-NLQP-2014 & Monofia & Farm & $3-2014$ & KU365655 \\
\hline $\mathbf{7}$ & NDV-3-EGYPT-NLQP-2013 & Behera & Backyard & $8-2013$ & KU365656 \\
\hline $\mathbf{8}$ & NDV-4-EGYPT-NLQP-2013 & Sharkia & Backyard & $6-2013$ & KU365657 \\
\hline $\mathbf{9}$ & NDV-5-EGYPT-NLQP-2013 & Cairo & Farm & $8-2013$ & KU365658 \\
\hline $\mathbf{1 0}$ & NDV-6-EGYPT-NLQP-2014 & Al-Gharbia & Backyard & $9-2014$ & KU365659 \\
\hline $\mathbf{1 1}$ & NDV-7-EGYPT-NLQP-2013 & Behera & Farm & $5-2013$ & KU365660 \\
\hline $\mathbf{1 2}$ & NDV-8-EGYPT-NLQP-2014 & Giza & Backyard & $10-2014$ & KU365661 \\
\hline $\mathbf{1 3}$ & NDV-9-EGYPT-NLQP-2014 & Bani-suaif & Farm & $11-2014$ & KU365662 \\
\hline $\mathbf{1 4}$ & NDV-31-EGYPT-NLQP-2014 & Sharkia & Backyard & $8-2014$ & KU365663 \\
\hline
\end{tabular}

\section{RESULTS}

\section{Clinical and necropsy findings}

Clinically, the most common clinical signs were greenish diarrhea surrounding the cloaca, respiratory (sneezing, gasping for air, nasal discharge and coughing), nervous signs (incoordination, tremors, torticollis, opisthotonusparalysis of wings and/or legs, twisting of head and neck or complete paralysis) and death. Most commonly observed PM lesions were varying degrees of congestion and swelling of respiratory and digestive tract, trachea and lungs showed congestion and hemorrhages in the mucosa. Marked hemorrhages on the tips of the proventriculus, button-like ulcers in the wall of intestine, cecal tonsils were enlarged, thickened, necrotic and hemorrhagic.

\section{Histopathology and immunohistochemistry}

The histopathological examination of brain, trachea, lungs, proventriculus, pancreas and small intestine of naturally infected birds in the current study in which brain showed congested blood vessels with edematous vacuoles, lymphocytic perivascular 
cuffing and diffuse gliosis in cerebral tissue was shown (Fig. 1A). Trachea, showed mild congested blood capillaries with mild edema in the mucosa with desquamation of epithelium and congested blood capillaries. The invading inflammatory cells were mononuclear (Fig.1B). Lungs, bronchial mucosa showed severe epithelial ulceration and necrosis. The invading inflammatory cells were rounding mononuclear in high populations which filled the parabronchial lumen. Blood vessels and alveolar blood capillaries were severely congested (Fig.1 C). Small intestine especially the duodenum showed severe epithelial ulcerations and sloughing of intestinal villi (Fig.1D). Pancreas showed multifocal necrosis of pancreatic acini (Fig.1E). Proventriculus, showed erosion and ulceration severe congestion and haemorrhage in mucosal epithelium. Diffuseinfiltrations of invading round inflammatory cells made thickening of mucosal and submucosal layers (Fig. 1 F).

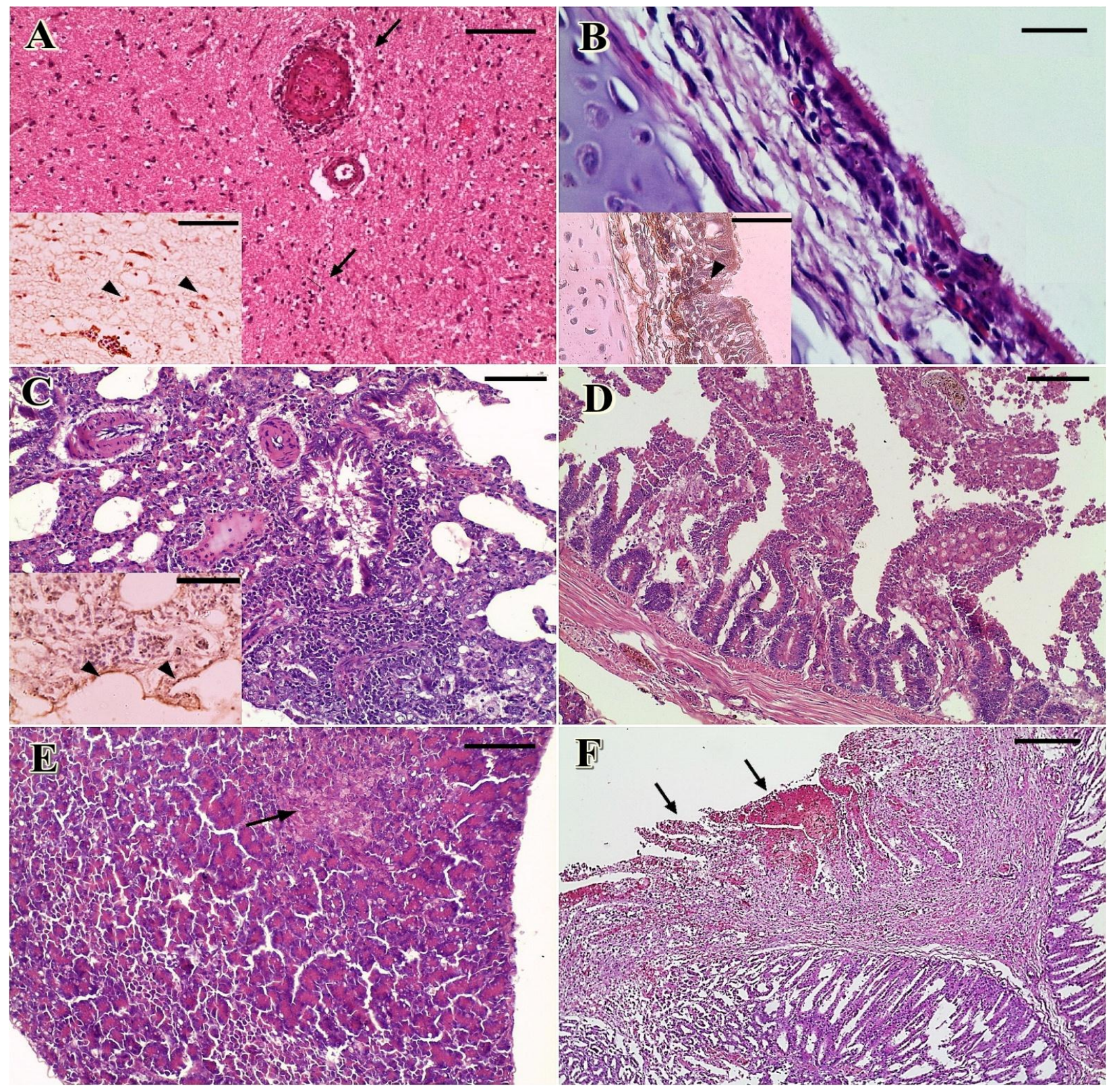

Fig.1: Histopathology and immunohistochemical staining for Newcastle virus antigen in tissues of chickens.

(A) Brain showing perivascular cuffing and gliosis (arrow) scale bar $100 \mu \mathrm{m}$, (insert) viral antigen (head arrow) is seen in neuron and glial cells in cerebrum scale bar $50 \mu \mathrm{m}$. (B) Trachea showing mild catarrhal tracheitis scale bar $200 \mu \mathrm{m}$, (insert) viral antigen in

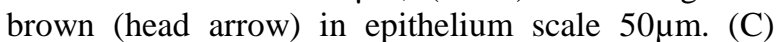
Lung showing severe interstitial pneumonia $100 \mu \mathrm{m}$, (insert) viral antigen in brown (head arrow) seen in alveolar (air) capillaries. (D) Small intestine showing severe necrosis of intestinal villi scale $100 \mu \mathrm{m}$. (E) Pancreas showing necrosis of pancreatic acinar epithelium (arrow) scale $100 \mu \mathrm{m}$. (F) Proventriculus showing mucosal haemorrhages (arrows) scale $40 \mu \mathrm{m}$. 


\section{Detection and amplification of NDV by PCR}

All collected samples (14) are positive by RRT-PCR using specific primers and probe for NDV with threshold cycle between 16.4 and 24.38 , By using specific designed primers for fusion gene RT- PCR amplification was done showing specific bands at 766 bp (Partial amplification) and 1700bp for full fusion on agarose gel.

\section{Sequence and phylogenetic analysis}

Sequence analysis of the PCR products revealed that all examined samples are closely related to the very virulent strains of NDV (Genotype VIId) and are compared with other strains published on Gene Bank on NCBI website indicate that all of them were closely related to Chicken/China/SDWF07/2011 strain with identity (98\%-99\%) (Table3). Analyses of these samples indicate presence of motif ${ }^{112} \mathrm{RRQKRF}^{117}$ inhypervariable region which is indicative of velogenic character of NDV strains.

Analysis of four samples of a total 1662 nucleotides encoding for 553 amino acid residues were identified in the complete coding region of the F-gene. Six potential N-glycosylation sites (Asn-X-Ser/Thr where
$\mathrm{X}$ is any amino acid except proline or aspartic acid) located at positions 85 to 87,191 to 193,366 to 368 , 447 to 449,471 to 473 and 541 to 543 were recognized. Twelve cysteine residues located at positions 25, 76, 199, 338, 347, 362, 370, 394, 399, 401, 424 and 523 were identified. Comparison of glycosylation sites and cysteine residues showed no changes in the amino acid sequence in all field strains, which may indicate that these sites were highly conserved. Analysis of seven neutralizing epitopes located at positions $72,74,75,78,79,157$ to 171 and 343 of the F-protein showed presence of these substitution mutations in the examined strains L13P, E74D and D170N (Table 5).

In relation to vaccinal NDV strains (Lasota, Hitchner, clone 30 and Avenu) used in Egypt which genetically genotyped as lentogenic strains of NDVs (class II genotype II), the strains obtained in this study (class II Genotype VIId) show distant degree of amino acids homology ranged from $82 \%$ to $83 \%$. While for the Vectormune ND vaccine (class II genotype I) the amino acids identity ranged from $85 \%-86 \%$, according to the full fusion amino acid sequences (Table 3).

Table 3: Identity $\%$ of strains under study with other vaccinal and Egyptian strains

\begin{tabular}{|c|c|c|c|c|c|c|c|c|c|c|c|}
\hline $\begin{array}{l}\text { Strain name } \\
\text { (Amino acids identity are } \\
\text { marked with bold numbers) }\end{array}$ & 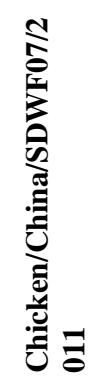 & 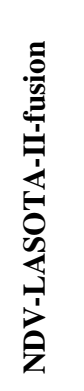 & 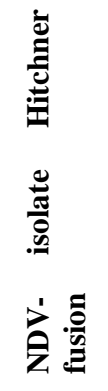 & 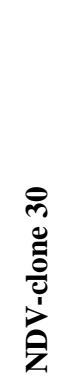 & 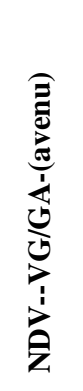 & 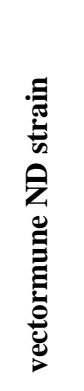 & 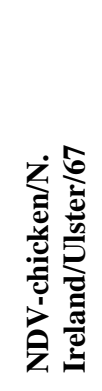 & 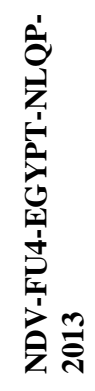 & 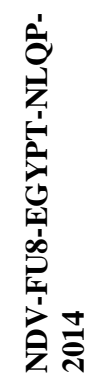 & 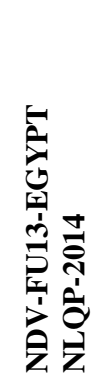 & 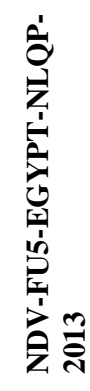 \\
\hline Chicken/China/SDWF07/2011 & & $88 \%$ & $89 \%$ & $88 \%$ & $88 \%$ & $91 \%$ & $90 \%$ & $99 \%$ & $99 \%$ & $96 \%$ & $97 \%$ \\
\hline NDV-LASOTA-II-fusion & $84 \%$ & & $100 \%$ & $98 \%$ & $99 \%$ & $93 \%$ & $93 \%$ & $87 \%$ & $88 \%$ & $86 \%$ & $86 \%$ \\
\hline NDV- isolate Hitchner fusion & $84 \%$ & $99 \%$ & & $98 \%$ & $99 \%$ & $93 \%$ & $93 \%$ & $88 \%$ & $88 \%$ & $86 \%$ & $86 \%$ \\
\hline NDV-clone 30 & $83 \%$ & $98 \%$ & $\mathbf{9 8 \%}$ & & $98 \%$ & $92 \%$ & $92 \%$ & $87 \%$ & $87 \%$ & $85 \%$ & $85 \%$ \\
\hline NDV--VG/GA-(avenu) & $84 \%$ & $99 \%$ & $100 \%$ & $97 \%$ & & $93 \%$ & $92 \%$ & $87 \%$ & $88 \%$ & $85 \%$ & $86 \%$ \\
\hline Vectormune ND strain & $86 \%$ & $89 \%$ & $90 \%$ & $\mathbf{8 8 \%}$ & $\mathbf{9 0 \%}$ & & $97 \%$ & $90 \%$ & $90 \%$ & $88 \%$ & $88 \%$ \\
\hline NDV-ch/N. Ireland/Ulster/67 & $86 \%$ & $90 \%$ & $91 \%$ & $89 \%$ & $90 \%$ & $95 \%$ & & $88 \%$ & $89 \%$ & $87 \%$ & $87 \%$ \\
\hline $\begin{array}{l}\text { NDV-FU4-EGYPT-NLQP- } \\
2013\end{array}$ & $99 \%$ & $83 \%$ & $83 \%$ & $82 \%$ & $83 \%$ & $86 \%$ & $85 \%$ & & $99 \%$ & $97 \%$ & $97 \%$ \\
\hline $\begin{array}{l}\text { NDV-FU8-EGYPT-NLQP- } \\
2014\end{array}$ & $99 \%$ & $83 \%$ & $84 \%$ & $83 \%$ & $83 \%$ & $86 \%$ & $85 \%$ & $99 \%$ & & $97 \%$ & $97 \%$ \\
\hline $\begin{array}{l}\text { NDV-FU13-EGYPT-NLQP- } \\
2014\end{array}$ & $\mathbf{9 8 \%}$ & $83 \%$ & $83 \%$ & $82 \%$ & $83 \%$ & $85 \%$ & $84 \%$ & $\mathbf{9 8 \%}$ & $\mathbf{9 8 \%}$ & & $95 \%$ \\
\hline $\begin{array}{l}\text { NDV-FU5-EGYPT-NLQP- } \\
2013\end{array}$ & $98 \%$ & $83 \%$ & $83 \%$ & $82 \%$ & $83 \%$ & $85 \%$ & $84 \%$ & $\mathbf{9 8 \%}$ & $\mathbf{9 8 \%}$ & $\mathbf{9 8 \%}$ & \\
\hline
\end{tabular}




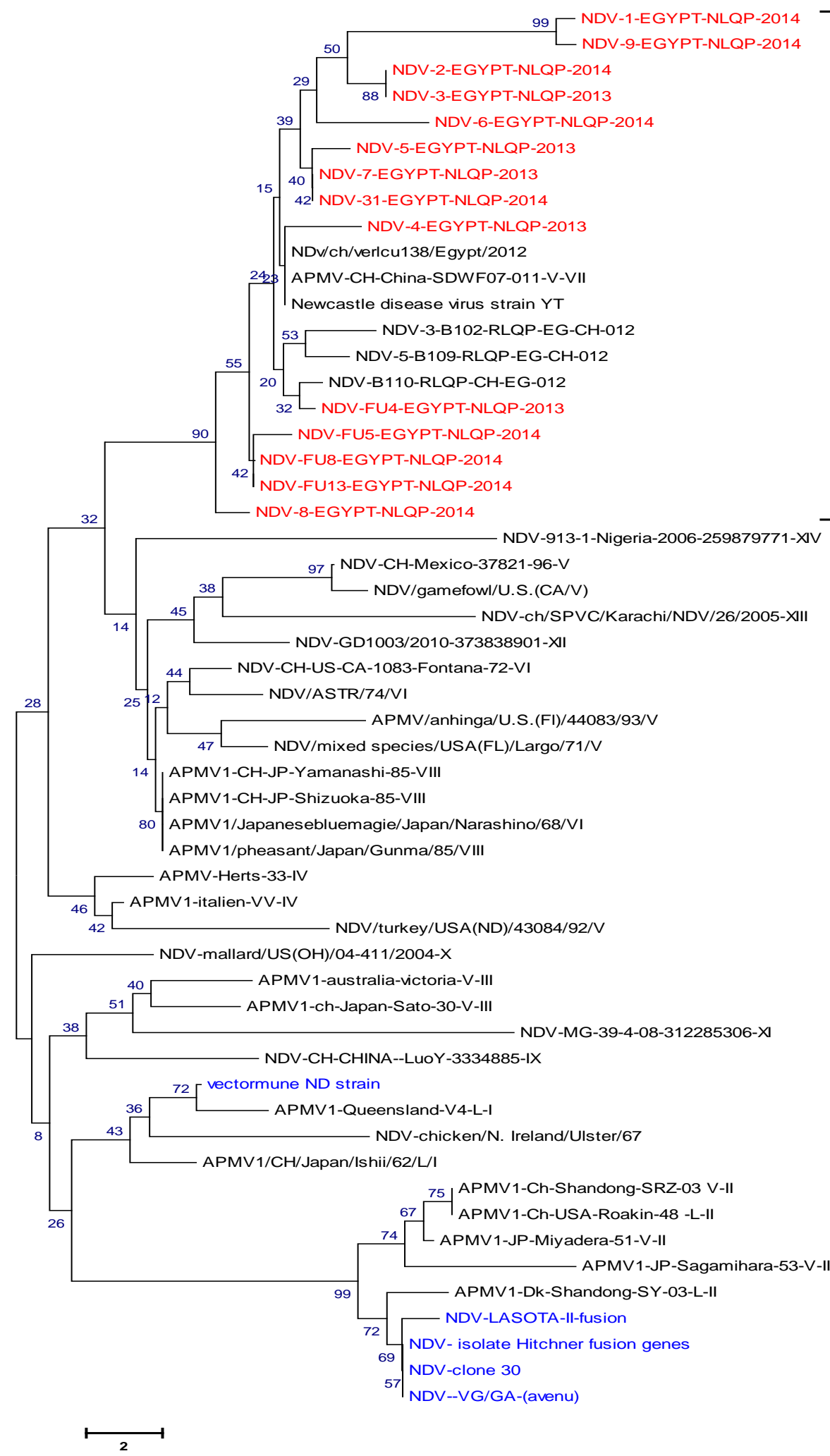

Fig. 2: Phylogenetic tree of partially sequenced NDV strains with other Egyptian and vaccinal strains and other strains from Middle East. 

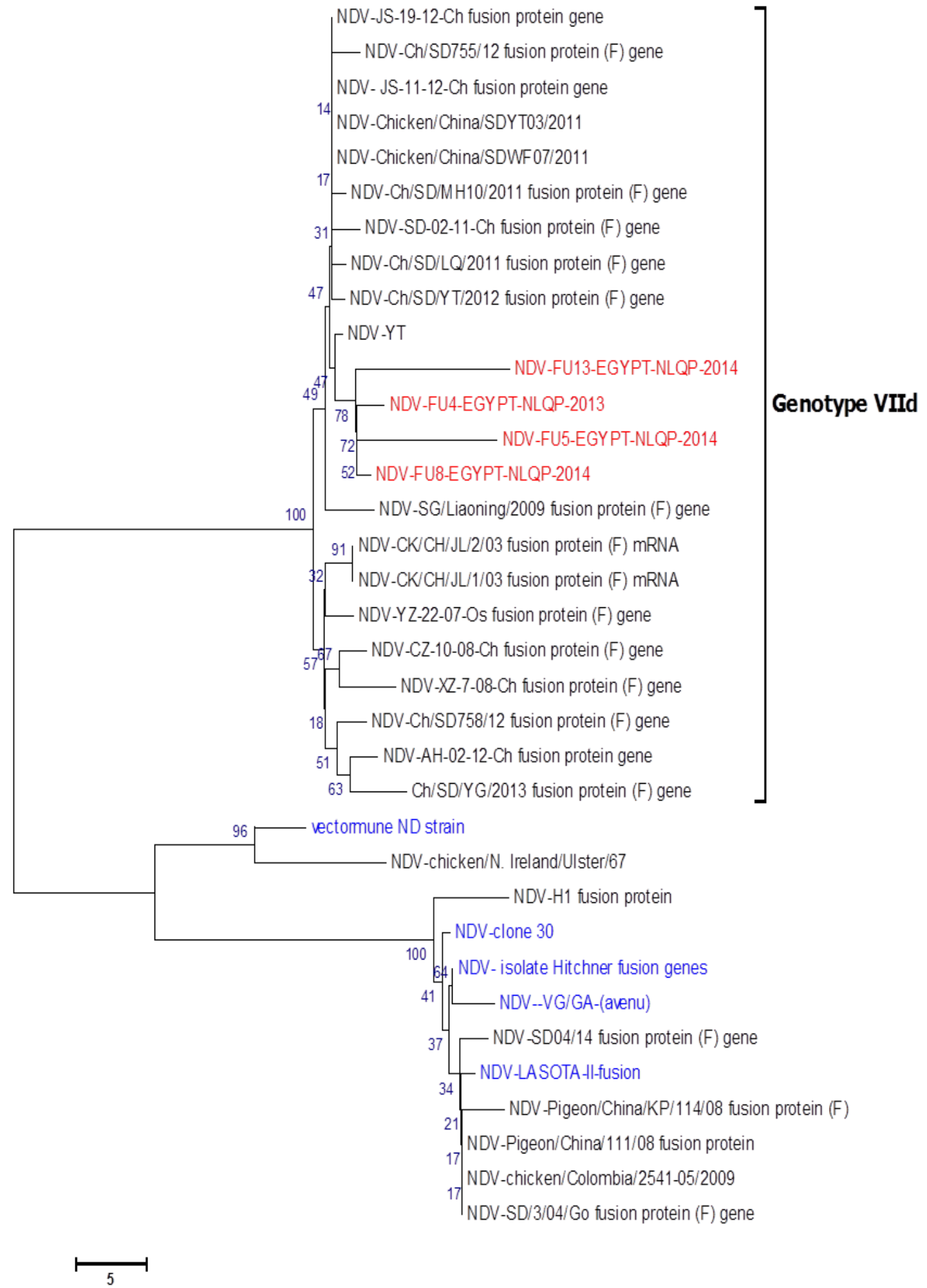

Fig. 3: Phylogenetic tree of fully sequenced NDV fusion gene strains with other vaccinal and reference strains. 
Table 4: Amino acid substitution in the variable region and neutralizing epitopes of the F-gene sequences of Egyptian strains.

\begin{tabular}{|c|c|c|c|c|c|c|c|c|c|c|c|c|c|c|c|c|c|c|c|c|}
\hline \multirow{2}{*}{$\begin{array}{r}\text { Virus } \\
\text { Position }\end{array}$} & \multicolumn{13}{|c|}{ Hyper-variable region } & \multicolumn{7}{|c|}{ Neutralizing epitopes } \\
\hline & 4 & 10 & 11 & 13 & 20 & 21 & 27 & 52 & 63 & 78 & 93 & 101 & 121 & 72 & 74 & 75 & 78 & 79 & 157-171 & $\overline{343}$ \\
\hline Consensus & $\mathbf{K}$ & $\mathbf{P}$ & $\overline{\mathbf{A}}$ & $\mathbf{L}$ & $\mathbf{M}$ & $\mathbf{L}$ & $\mathbf{R}$ & $\mathbf{V}$ & $\mathbf{V}$ & $\mathbf{R}$ & $\mathbf{T}$ & $\mathbf{K}$ & $\mathbf{V}$ & $\mathbf{D}$ & $\mathbf{E}$ & $\mathbf{A}$ & $\mathbf{R}$ & $\mathbf{A}$ & SIAATNEAVHEVTD & $\overline{\mathbf{L}}$ \\
\hline $\begin{array}{l}\text { NDV-FU4- } \\
\text { EGYPT- } \\
\text { NLQP-2013 }\end{array}$ & - & - & - & $\overline{\mathbf{P}}$ & - & - & - & - & - & - & - & - & - & - & - & - & - & - & 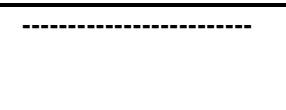 & - \\
\hline $\begin{array}{l}\text { NDV-FU8- } \\
\text { EGYPT- } \\
\text { NLQP-2014 }\end{array}$ & - & - & - & - & - & - & - & - & - & - & - & - & - & - & - & - & - & - & SIAATNEAVHEVTN & - \\
\hline $\begin{array}{l}\text { NDV-FU13- } \\
\text { EGYPT- } \\
\text { NLQP-2014 }\end{array}$ & - & - & - & - & - & - & - & - & - & - & - & - & - & - & - & - & - & - & 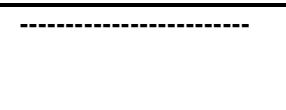 & - \\
\hline $\begin{array}{l}\text { NDV-FU5- } \\
\text { EGYPT- } \\
\text { NLQP-2013 }\end{array}$ & - & - & - & - & - & - & - & - & - & - & - & - & - & - & $\mathbf{D}$ & - & - & - & 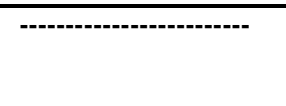 & - \\
\hline
\end{tabular}

\section{DISCUSSION}

Newcastle disease (ND) is the most divesting disease affecting poultry especially in large scale production (Alexander et al., 2003). Egypt is endemic for Newcastle disease virus (NDV) with continuous longlasting outbreaks causing significant economic losses in the poultry industry due to high mortality which may reach $100 \%$ in very virulent strains of NDV, despite the intensive vaccination programs (Mohamed et al., 2011; Radwan et al., 2013; Nabila et al., 2014 and El Bagoury et al., 2015). The use of rRT-PCR and other similar techniques for the determination of the virulence of ND viruses and for Phylogenetic studies has been reported (Farkas et al., 2009), there is increasing use of such molecular techniques to detect NDV in clinical specimens with its advantage being the extremely rapid demonstration of the presence of virus (OIE, 2009).

Based on clinic-pathological findings indicatesthat examined NDV strains of considerable virulence and is comparable to many other highly velogenic viscerotropic NDV strains. Principal gross lesions consisted of severe nervous manifestation, visceral hemorrhages, respiratory symptoms and splenic necrosis all of whichare consistent with other velogenic viscerotropic NDV strains (Cattoli et al., 2011). Histologically, NDV strains behaved as a typical highly virulent strain, with extensive interstitial pneumonia, severe enteritis, gliosis with neuronal degeneration and necrosis of lymphoid tissues, especially those of the spleen. By immunohistochemistry, showed positive tissues indicating a marked systemic pantropism, which is also typical of highly virulent NDV strains (Susta et al., 2011 and cattolli et al., 2011).

Evolution of NDV may be related to the accumulation of point mutations that induce amino acid substitution in the neutralizing epitopes as the Nlinked glycosylation sites of the $\mathrm{F}$ protein (Chambers et al., 1986). F-Protein of virulent strains differ from those of a virulent virus by virtue of possessing a pair of dibasic amino acids at the carboxyl (C) terminus of F2 and phenylalanine at residue 117 which is the $\mathrm{N}$ terminus of the F1 protein. The term 'multiple basic amino acids' refers to at least three arginine $(\mathrm{R})$ or lysine $(\mathrm{K})$ residues between residues 113 and 116 while a virulent viruses have Leu (leucine) at amino acid no.117 cleavage site in their fusion protein (Collins et al., 1993 and Zhu et al., 2010).

Genotype VII (class II genotype VII) was firstly categorized into two subgenotype: VIIa, which represents viruses that emerged in the 1990s in the Far East and spread to Europe and Asia; and VIIb, which represents viruses that emerged in the Far East and spread to South Africa. Later, the two subgenotypes of VII are classified into VIIc, d, and e, which represents isolates from China, Kazakhstan and South Africa; and VIIf, g, h, and i, which represent African isolates (De Almeida et al., 2009 and Miller et al., 2010).

Analysis of the deduced amino acid sequence and phylogenetic analysis of the NDV F-gene of the strains isolated from Egypt in 2013 and 2014 suggests that all examined samples close to genotype VIId circulating in the Middle Eastern countries and China, which is responsible for the continuing outbreaks of ND in Egypt (Nabila et al., 2014 and Hussien et al., 2014). This is confirmed by presence of Serin at site 176 which is recorded as specific signature to cluster VII. Exclusive Amino acid and nucleotide signatures of genotype VIId are V52, I255, Y314, T1044, G1608 (De Almeida et al., 2013) that are recorded in strains under study. Seven major epitopes have been identified involving the fusion inhibition and neutralization of F-protein (Neyt et al., 1989 and 
Yusof et al., 1989). Individual amino acids at 72, 74, $75,78,79$ and 343 and a stretch of amino acids from residues 157-171 were identified to be critical for both structures and functions of the F-gene (Yusoff K et al., 1989). In this study, nucleotide substitution in one of the fusion inhibition and neutralizing epitope (K78R) was identified in all VIId strains and present in 4 strains under study. Comparison with sequence data from reference strains showed that among these mutations, K4I were conserved only in NDV strains originating from Japan while L21P, I52V, K78R and $\mathrm{R} 101 \mathrm{~K}$ were conserved in strains originating from the Far East Asia (Japan, China and Taiwan). These substitutions maybe used as crude molecular markers of geographic origins of NDVs (Dennis et al., 2013).

When compared the $\mathrm{F}$ gene of strains under study (genotype VII) with vaccine strain like La Sota, two of these epitopes were changed as follows: E74D in NDV-FU5-EGYPT-NLQP-2014 and D170N in NDV-FU8-EGYPT-NLQP-2014, which displayed the antigenic difference and considered as escape mutants that may affect antigenicity of these viruses (Renata et al., 2013).

A point mutation in the F-gene may have resulted to neutralizing epitope variants However, it is unclear if these mutations were a part of adaptive mechanism of NDVs to evade the immune response to be able to infect vaccinated chickens, or whether this mutation was actually the effect of selective immune pressure exerted on ND viral particles as a consequence of vaccination. To understand how wild NDVs infect vaccinated chickens, this identified mutation may be useful for future site-directed mutagenesis studies (Dennis et al., 2013).

The NDV can occur in vaccinated birds because some of the birds will have had a poor vaccine response and will be susceptible to infection. This attributed to ND vaccines do not protect vaccinates from infection and viral shedding. Also, parental immunity contributed to vaccination inefficiency in young chicks (Kapczynski and King, 2005). Vaccination failure due to inefficient vaccination or virus genetic drift should be considered to draft the efficiency of the commercial available vaccines against these isolates or to prepare a new one.

In conclusion, data obtained hereconfirm highcirculation of genotype VII which became the predominant strain and causing the severe outbreaks in poultry farms, which may be originated from south East Asian countries. Vaccines and vaccination programs evaluation should be repeated. Continuous monitoring of the flocks' immunological status should be carried out to evaluate the antibody response to currently used vaccines.

\section{REFERENCES}

Alexander, D.J.; Saif, Y.M.; Barnes, H.J.; Fadly, A.M.; Glisson, J.R.; McDougald, L.R. and Swayne, D.E. (2003): Diseases of poultry chapter (Newcastle disease, other avian paramyxoviruses, and pneumovirus infections). 11th ed. Iowa State University Press, Ames, Iowa. pp. Page 63-92.

Ausvetplan, (2006): Australian Veterinary Emergency Plan: Disease Strategy, Newcastle disease, edition 3, Primary Industries Ministerial Council, Canberra, ACT. Version 3.1, 2006.

Cattoli, G.; Susta, L.; Terregino, C. and Brown, C. (2011): Newcastle disease: a review of field recognition and current methods of laboratory detection. J. Vet. Diagn Invest. 2011 Jul; 23(4): 637-56. doi: 10.1177/ 1040638711407887

Chambers, P.N.S. Millar; Simon, G. Platt and Emmerson, P.T. (1986): Nucleotide sequence of the gene encoding the matrix protein of Newcastle disease virus. Nucleic Acids Res. 1986; 14 (22): 9051-9061.

Collins, M.S.; Bashiruddin, J.B. and Alexander, D.J. (1993): Deduced amino acid sequences at the fusion protein cleavage site of Newcastle disease viruses showing variation in antigenicity and pathogenicity. Arch Virol. 1993; 128(3-4): 363-70.

Creelan, L.J.; Graham, D.A. and McCullough, Samuel J. (2002): Detection and differentiation of pathogenicity of avian paramyxovirus serotype 1 from field cases using one-step reverse transcriptasepolymerase chain reaction. Avian Pathology, 31: 5, 493-499.

De Almeida, R.S.; Maminiaina, O.F.; Hammoumi, S.; Molia, S.C.; Koko, M.; Andriamanivo, H.R.; Traore, A.; Samake, K.; Diarra, A.; Grillet, C.; Martinez, D. and Albina, E. (2009): Africa, a reservoir of new virulent strains of Newcastle disease virus? Vaccine 27, 3127-3129 (2009).

De Almeida, RS.; Hammoumi, S.; Gil, P.; Briand, F$X$. and Molia, S. et al. (2013) New Avian Paramyxoviruses Type I Strains Identified in Africa Provide New Outcomes for Phylogeny Reconstruction and Genotype Classification. PLoS ONE 8(10): e76413. doi: 10. 137 1/ jo urn al. pone .0076413 .

Dennis Villaseñor Umali; Hiroshi Ito; Terumasa Suzuki; Kazutoshi Shirota; Hiromitsu Katoh, and Toshihiro Ito (2013): Molecular epidemiology of Newcastle disease virus isolates from vaccinated commercial poultry farms in non-epidemic areas of Japan, Virol J. 2013; 10: 330. Published online 2013 Nov 9. 
doi: $\underline{10.1186 / 1743-422 X-10-330}$ PMCID: PMC 3831826.

El-Bagoury Gabr, F.; Samar, F. El-Adaway; Ayman, S. El-Habbaa and Susan, S.El-Mahdy. (2015): Isolation, identification and pathotyping of Newcastle disease virus from chickens in Egypt. Benha Vet. Med. J., Vol. 29, No. 1: 196-204.

Farkas, T.; Székely, É. and Belák. S. (2009): Realtime PCR based pathotyping of Newcastle disease virus (NDV) using TaqMan Minor Groove Binder (MGB) probes. J. Clin. Microbiol. 2009 July; 47(7): 2114-2123.

Hussien, A.H.; Emara, M.M. and Rohiem, M.A. (2014): Molecular characterization of Newcastle disease virus genotype VIID in avian influenza $\mathrm{H}_{5} \mathrm{~N}_{1}$ infected broiler flock in Egypt. International journal of virology 10(1): 46-54, 2014.

Kapczynski, D.R. and King, D.J. (2005): Protection of chickens against overt clinical disease and determination of viral shedding following vaccination with commercially available Newcastle disease virus vaccines upon challenge with highly virulent virus from the California 2002 exotic.

Lamb, R.A. and Parks, G.D. (2007): Paramyxoviridae: the viruses and their replication, 2007, p. 1449-1496. In D.M. Knipe and P.M. Howley (ed.), Fields virology, 5th ed. Lippincott Williams \& Wilkins, Philadelphia, PA.

Madadger, O.V.; Karimi, A.; Nazaktabar, A.; Kazemimanesh, M.; Dezfouli, M.M.; Azimi, S.M. and Hojjati, P. (2013).A study of Newcastle disease virus obtained from exotic caged birds in Tehran between 2009 and 2010. Avian Pathol. 42(1):27-31

Mohamed, M.H.A.; Sachin Kumar; Anandan paldurai; Mohamed. M. Megahed; Ibrahim, A. Ghanem; Mohamed. A. Lebdah and Siba K. Samal, (2009): Complete genome sequence of avirulent Newcastle disease virus isolated from an outbreak in chickens in Egypt. Virus genes (2009) 39: 234-237.

Mase Masaji; Kunitoshi Imai; Yasuyuki Sanada; Naoko Sanada; Noboru Yuasa; Tadao Imada; Kenji Tsukamoto and Shigeo Yamaguchi. (2002): Phylogenetic Analysis of Newcastle Disease Virus Genotypes Isolated in Japan, J. clini. microbiol., Vol. 40, no. 10, p. 38263830 .

Mayo, M.A. (2002): Virus taxonomy-Houston 2002. Arch. Virol. 147: 1071-1076.

Miller, PJ.; Decanini, EL. and Afonso, CL. (2010): Newcastle disease: evolution of genotypes and the related diagnostic challenges. Infect Genet Evol 10: 26-35.

Morrison, T.; McQuain, C.; Sergel, T.; McGinnes, L. and Reitter, J. (1993): The role of the amino terminus F1 of the Newcastle disease virus fusion protein in cleavage and fusion. Virology, 193: 997-1000.

Neyt, C.; Geliebter, J.; Slaoui, M.; Morales, D.; Meulemans, G. and Burny, A. (1989): Mutations located on both F1 and F2 subunits of the Newcastle disease virus fusion protein confer resistance to neutralization with monoclonal antibodies. J. Virol, 63: 952-954.

OIE, (2009): Newcastle disease, chapter 2.3.14, volume (1) section (2-3). page: 576-589.

OIE. (2012): Newcastle disease. In Manual of diagnostic tests and vaccines for terrestrial animals. OIE, Paris, France. http://www. oie.int/ fileadmin /Home/ eng Health standards/tahm/2.03.14_NEWCASTLE_DIS. pdf.

Osman Nabila; Serageldeen Sultan; Ahmed I. Ahmed; Ragab S. Ibrahim and Mahmoud Sabra (2014): Isolation and Pathotyping of Newcastle Disease Viruses from Field Outbreaks among Chickens in the Southern Part of Egypt 2011-2012. Global Veterinaria 12 (2): 237-243, 2014.

Radwan, M.M.; El-Sanousi, A.A.; Darwish, S.F.; Shalaby, M.A.; El-Sabagh, I.M. (2013): Isolation and molecular characterization of Newcastle disease virus genotypes II and VIId in Egypt between 2011 and 2012. Virus Genes (2013) 47: 311-316.

Rezaeianzadeh, G.; Dadras, H.; Safar, A.; Ali, M. and Nazemshirazi, MH. (2011): Serological and molecular study of Newcastle disease virus circulating in village chickens of Fars province, Iran. J. Vet. Med. Anim. Health 3(8): 105-111.

Renata Servande Almeida.; Saliha Hammoumi.; Patricia Gill; Franc, ois Xavie rBri and, Sophie Molia; Nicolas Gaidet; Julien Cappelle; Ve'ronique Chevalier; Gilles Balanc; a, Abdallah Traore'; Colette Grillet; Olivier Fridolin Maminiaina; Samia Guendouz; Marthin Dakouo; Kassim Samake'; Ould El Mamy Bezeid; Abbas Diarra; Hassen Chaka; Flavie Goutard; Peter Thompson; Dominique Martinez; Ve'ronique Jestin and Emmanuel Albina (2013): New Avian Paramyxoviruses Type IS trains Identified in Africa Provide New Outcomes for Phylogeny Reconstruction and Genotype Classification.

Rott, R. and Klenk, H.D. (1988): Molecular basis of infectivity and pathogenicity of Newcastle disease virus. In. D.J. Alexander (ed.), Newcastle disease, Kluwer Academic Publishers, Boston. pp. 98-112.

Susta, L.; Miller, P.J.; Afonso, C.L. and Brown, C.C. (2011): Clinicopathological characterization in poultry of three strains of Newcastle disease virus isolated from recent outbreaks. Vet. Pathol. Mar; 48(2): 349-60. 
Tamura, K.; Stecher, G.; Peterson, D.; Filipski, A. and Kumar, S. (2013): MEGA6: molecular evolutionary genetics analysis version 6.0 . Mol. Biol. Evol 30, 2725-2729.

Yusoff, K.; Nesbit, M.; Mc Cartney, H.; Meulemans, G.; Alexander, DJ.; Collins, MS.; Emmerson, PT. and Samson, AC. (1989): Location of neutralizing epitopes on the fusion protein of Newcastle disease virus strain beaudette C.J.
Gen Virol. 1989;10: 3105-3109. doi: 10.1099 /0022-1317-70-11-3105.

Zhu, W.; Dong, J.; Xie, Z.; Liu, Q. and Khan MI. (2010): Phylogenetic and pathogenic analysis of Newcastle disease virus isolated from house sparrow (Passer domesticus) living around poultry farm in southern China. Virus genes, 40 (2): 231-5.

\section{التوصيف الجينى والباثولوجى لفيروس النيوكاسل يكثف انتشار العترة شديدة الضراوة من النوع V

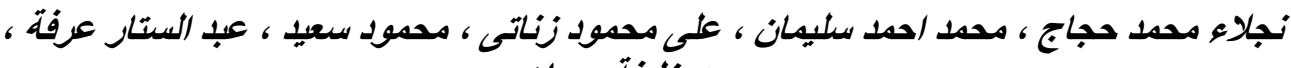

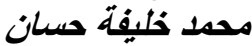

\section{Email: naglaavetrose@yahoo.com Assiut University web-site: $\underline{w w w . a u n . e d u . e g}$}

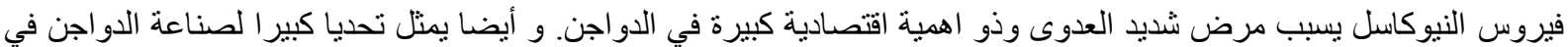

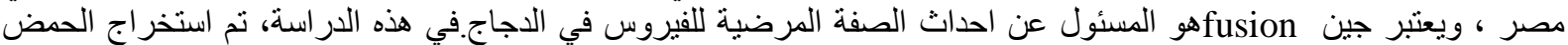

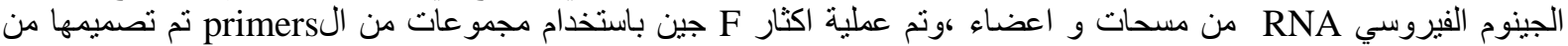

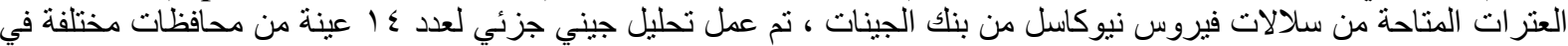

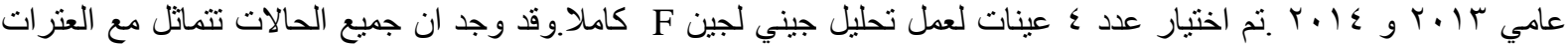

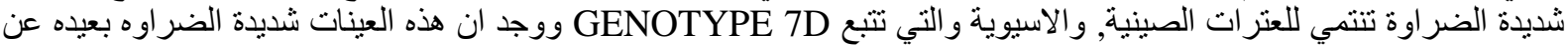
العتر ات المستخدمة فى التحصين ولذلك فانه يجب علين التينا مر اجعه التحصينات الموجودة في مصر. 